\title{
A Cost-Efficiency Analysis of European Air Navigation Service Providers.
}

Zara Dempsey-Brench: zara.dempsey-brench@ba.com British Airways, Waterside (HBA1), Harmondsworth, Middlesex, PO Box 365, UB7 0GB, UK

Nicola Volta: n.volta@cranfield.ac.uk - CORRESPONDING AUTHOR

Cranfield University, Centre for Air Transport Management, University Way, Cranfield, Bedfordshire MK43 0TR, UK.

\begin{abstract}
Air Navigation Service Providers (ANSPs) as the third major component of the aviation industry have been less of a focus in research than their airline and airport counterparts. In this paper we analyse European ANSPs cost structures using a stochastic frontier analysis approach within a Bayesian estimation framework in order to incorporate regularity conditions. Our results show that ownership is not directly impacting neither the ANSPs cost structures nor their cost efficiencies and the European ANSPs are operating on the increasing return to scale part of the technology, hence supporting the choice of ANSPs agglomeration.
\end{abstract}

\section{Keyword}

Bayesian estimation, stochastic frontier analysis, cost function, air navigation service providers, ownership 


\section{Introduction}

Air Navigation Service Providers (ANSPs) are the third major component within the aviation industry, connecting the other two components; airlines and airports through their provision of air navigation services (ANS) whilst ensuring the safety of operations and the promotion of efficient traffic flows. ANSPs are entities providing both air traffic control (ATC) and air navigation services (ANS) collectively referred to as air traffic management (ATM) (Oster and Strong, 2007). ANSPs offer en-route, approach and aerodrome control air traffic services. Many also offer oceanic ANS and some provide services to civil and military aviation. As a result, ANS can account for between five and ten percent of airlines operating costs, with delays generating significant costs to the airlines (Quendt et al., 2007). Considering this, it is recognised that improvements for the enhancement of flight and airspace efficiencies will facilitate significant cost savings within the industry (McDougall and Roberts, 2008). Historically, ANSPs have been owned and controlled by their respective governments. However, there is a trend towards separation from the government and a commercialisation of the ANSP organisations, with many ANSPs world-wide having moved from the traditional governmental departments and agencies towards various different organisational forms with some degree of commercial focus within their service provision. This is often a result of increasing financial constraints faced by governments, increased congestion and outdated equipment and facilities. As such within Europe, several ANSPs have undergone institutional reform to become commercialised allowing them to generate internal improvements and liberating them from governmental budgetary controls which in turn should enable benefits and efficiencies for the airspace users. Most ANSPs have already diversified into non-core business activities, with some explicitly stating intentions of expanding such activities. As such, it is interesting to determine the impact, if any, that the commercialisation, privatisation and resultant non-core business activities may have upon the cost-efficiencies which they seek. A number of publications and studies have tried to assess the contribution which privatisation and commercialisation can have on the provision of ANS both within Europe and world-wide. For example, Lewis and Zolin (2004) undertook a comparative analysis of the institutional arrangements for governance of several global ANSPs ascertaining that privatisation is directly related to the ANSP's ability to respond to user needs. They suggest that privatisation should lead to the improvement of financial performances, safety and efficiency. Button and McDougall (2006) indicate that in the long-term, ANSP commercialisation results in reductions in charges levied on customers, achieved through competition. Their study suggests that commercialisation often leads to improvements of service portfolios and provides flexibility. Similar results are provided in McDougall and Roberts (2008); the authors suggest that ANSP commercialisation generally achieves service quality improvements, modernisation of technologies, financial stability and high safety levels. When turning the attention towards ANSP cost efficiency, few studies have tried to analyse the European air navigation system. EUROCONTROL, a European 
regulation body providing member states with guidance to achieving safe, efficient and environmentally sound air traffic services, ${ }^{1}$ produces a benchmark analysis of ANSPs. They publish reports which monitor performance and targets for improvements, including the annual Air Traffic Management Cost Effectiveness (ACE) benchmarking report which mainly compares ANSPs on financial and economic gate-to-gate key performance indicators. Besides these reports, EUROCONTROL performance review unit (PRU) commission studies on the efficiency of air navigation systems such as those by Mouchart and Simar (2003), NERA Economic Consulting (2006) and Competition Economists Group (2011). Mouchart and Simar (2003), focus on the technical efficiency of European air control centres (i.e. the regional centres composing the ANSPs) applying a non-parametric methodology. The main conclusions of the report are that the efficiency of the Centres are similar to the year 2000 and that the delay variable has a significant effect on the individual inefficiencies. Finally, the authors argue that the returns-to-scale in the production process of the Centres are characterised by increasing or near constant returns-to-scale for small units and decreasing returns-to-scale for larger Centres. NERA (2006) and the Competition Economists Group (2011) are, to the best of our knowledge, the only two works estimating European ANSPs cost efficiency using a stochastic frontier approach. NERA (2006) compared the cost efficiency of 34 ANSPs between 2001 and 2004 using a Cobb Douglas functional form, however the results were considered to be poor given the insufficient number of observations and no major conclusions were drawn. Similarly, the Competition Economists Group (2011) assessed ANSP cost-efficiency extending the previous work by NERA. The report analysed the cost efficiency of ANSPs for the period 2002-2009 applying a Cobb Douglas total cost stochastic frontier analysis. Despite problems of estimation convergence, the report shows an average level of inefficiency ranging from $13 \%$ to $60 \%$, as a function of the assumption with respect to the inefficiency distribution. Besides these works, few other researchers benchmarked European ANSPs applying a data envelopment approach (e.g., Button and Neiva, 2014, Bilotkach et al., 2015). Generally, no research has been undertaken in order to connect ownership and efficiency by showing the influence that ownership and institutional structure has upon ANSP (cost) efficiency. The aim of this research is to fill this gap in the literature. By adopting a stochastic frontier approach, we evaluate the impact of ownership over the ANSPs cost structures and cost efficiencies. We estimate the cost functions (total cost and variable cost) within a Bayesian framework in order to incorporate regularity conditions following the economics theory. By satisfying the economics regularity assumptions, our estimates are therefore providing useful information to the regulator in regards to industry elasticities and economies of scale.

\footnotetext{
${ }^{1}$ Notice that EUROCONTROL includes as members some non-EU countries (e.g. Armenia, Albania, Ukraine, etc.)
} 


\subsection{European ANSPs}

ANS within Europe are coordinated and integrated by EUROCONTROL. EUROCONTROL aims to facilitate the establishment of a Single European Sky (SES), a European Union initiative looking to address issues facing the European ATM system including increasing traffic levels, high costs of ANSP services, heterogeneous working practices and constraints of air route networks. Although a controversial concept, with possibilities of workforce redundancies, the SES looks to restructure and defragment the European airspace to enhance capacity and enable a more efficient air navigation system. The SES has introduced the concept of Functional Airspace Blocks (FABs) with the intent to increase cooperation and integration of ANS provision amongst ANSPs, or, in cases, through an integrated provider. This concept aims to reorganise the current airspace blocks across Europe which are established according to national boundaries into nine functional airspace blocks, thereby defragmenting the European airspace. The SES legislative package most notably Regulation EC No. (1070/2009) defines FABs as an airspace block which is developed in accordance with operational requirements irrespective of national boundaries enabling the provision of ANS and associated functions to be performance-driven and optimised. Moreover, SES has resulted in the European Commission deciding on common regulatory approaches and they oversee implementation at national level, with a focus on performance regulations to stimulate ANSP cost-efficiency and service quality. As an example, prior to 2012 the ANSP charges were regulated under full cost-recovery mechanisms resulting in increased charges following any revenue shortfalls and with any profits redistributed to the airspace users (European Commission, 2010). In accordance with the more recent regulation $1191 / 2010$, ANSPs are now not guaranteed to cover their costs and they have incentives to be efficient given the possibility of retaining profits. However, despite being directed by rules and business pressures prescribed by EUROCONTROL, ANSPs within Europe still differ significantly. Each ANSP has duties mandated by laws unique to them, with governments providing different definitions and responsibilities of their respective ANSPs. Almost all ANSPs are engaged in both core and non-core business activities, however, the extent to which varies across each ANSP.

\subsection{ANSPs Privatisation and Commercialisation}

It is possible to recognise three main ANSP ownership and institutional structures: state entities, commercialised organisations and privatised organisations. State entities are those which are considered a governmental department. Commercialised organisations can vary in type, for example, they can operate as an autonomous public sector entity, or may be a fully government owned entity which operates under private laws. Privatised organisations are those which have shares which are majority held by non-government companies such as stakeholders and private parties. Generally, 
privatisation can be defined as the change in ownership from government/state-owned to private ownership while commercialisation can be defined as a process in which the management style of an organisation is assessed and re-organised to ensure it is efficient, productive and profitable. The commercialisation of ANSPs originated in New Zealand in 1987, who created a state-owned enterprise paying dividends to the state. Australia then followed suit, and later, Canada who privatised their ANSP, NAV CANADA. Since, numerous ANSPs world-wide have become commercialised, most of which becoming 100\% state-owned corporations without profit-maximising goals. An exception to this is the UK's ANSP, NATS, which in 2001 became the first for-profit ANSP, operating under a public-private partnership. European ANS showed a trend towards commercialisation and government independence, with numerous European ANSPs considering themselves explicit commercial businesses seeking commercial opportunities. Privatisation and commercialisation look to improve efficiencies through the introduction of competitive behaviours within the environment. It has been argued that there is no potential for competition within the ATC environment due to its dependence upon infrastructure and reasons of national interest. However, arguably, given the open trading market within Europe, competition for the market does exist, such as the 2014 bid between NATS (UK) and DFS (Germany) ANSPs for the management of ATC services at Gatwick Airport, which was awarded to Germany's DFS. Commercial revenues could improve enroute service unit rates. As such, increased competition coupled with a commercial drive should result in reduced user fees in accordance with the cost-efficiency targets set by the European Commission. Another reason which identified the need for ownership reform was recognition that there was a direct conflict between the needs of ATC customers, politicians, industry and lobbies. Commercialisation is recognised by many advocates as a powerful catalyst for promoting collaboration between airspace users. Furthermore, it was considered necessary to separate service provision from economic and safety regulation as state civil aviation authorities were often regulating their competitors (Majumdar, 1995). A prime reason to move towards an ANSP entity separated from the government is to free the organisation from government funding and management constraints, enabling the required high levels of investment for the inherent technological dependency of ANSPs and to ensure that growing traffic levels can be safely controlled without resultant delays (Majumdar, 1995). Theoretically, a privatised entity would be financially self-sufficient and would have the potential to reduce service disruptions stemming from financial constraints and budget limitations. Suggested drawbacks of privatisation and commercialisation include the imposing of greater costs for airspace users, increased technological faults and disruptive labour disputes. However, it may be argued that privatisation cannot improve efficiencies and that profit-making incentives may contradict high levels of safety and security. The cost reductions resulting from ANSP privatisation (if any) may come at a detriment to other operational and organisational aspects. Monopolistic, revenue-driven entities tend to have little incentive to ensure fees are kept as low as possible whilst the labour-intensive nature of ANSPs 
contradicts the minimisation strategy of privatisation to keep costs low, as safety levels are the highest priority and reductions in workforce may implicate safety levels. Another problem related to the market characteristics can be depicted from the classic study by Vickers and Yarrow (1991). The authors suggest that private ownership has efficiency advantages only under competitive conditions, while ownership (whether private or public) in context of high market power is almost irrelevant. Indeed, in the case of natural monopolies (or geographical monopolies as for ANSPs), the only factor that appears to be relevant to impact efficiencies is the regulatory policy framework. Another significant problem in the trend towards privatisation and commercialisation is the political will of governments to allow independence of the ANSP. Governments are concerned about losing revenue and political influence that it can levy over ANS provision. An argument against privatisation and commercialisation is that government owned and controlled ANSP services allow budgets to be managed more simply, furthermore, the absence of commercial pressures ensures the removal of distraction from the core services. As a public service, significant ATC service failures would be catastrophic to respective countries. As such despite handing operational responsibility, assets and infrastructure to external parties, governments with privatised ANSPs still assume costs and ultimate responsibility to ensure continuous service.

\section{Methodology}

In order to study the impact of ownership on cost it is necessary to firstly define the ANSP's cost functions. Given the high variability of air traffic growth, ANSPs are constantly exposed to unanticipated traffic changes. Even if ANSPs are able to adjust inputs (at least to a certain degree) by accelerating or decelerating staff training and recruitment, this may not be valid when managing airspace capacity. During periods of low demand, it is not practical or sensible for ANSPs to cut capacity in order to save costs while, on the contrary, capacity enhancements are generally managed by long-term, capital intensive projects. Equation (1) describes a variable cost approach assuming the inability to fully adjust the input mix in the short run hence considering the capital as a quasi-fixed variable:

$$
V C=f(W, Y, K, Z)
$$

where the variable costs (VC) are a function of the set of input prices (W), the outputs (Y), the capital stock $(\mathrm{K})$ and a set of variables capturing the heterogeneity of the ANSPs (Z). Equation (1) by construction is only analysing the variable costs hence describing the cost of operating the capacity and the amount of capacity provided. By estimating a total cost function equation (2) it is possible to include the cost of supplying the capacity, hence providing a more complete analysis. The total cost approach in the most used within ANSP cost analysis, thereby assuming that the quantities of the 
inputs are freely available and under the control of the ANSPs (NERA, 2006, Competition Analysis Group, 2012 and Bilotkach et al., 2015).

$$
T C=f(W, Y, Z)
$$

The total costs (TC) are a function of a set of input prices including the price for the capital (W), the outputs (Y) and a set of set of variables controlling for heterogeneity (Z). We estimate the cost function (1) and (2) within a stochastic frontier framework, hence including inefficiencies as deviations from the optimal cost minimiser function:

$$
\begin{aligned}
V C & =f(W, Y, K, Z)+v+u \\
T C & =f(W, Y, Z)+v+u
\end{aligned}
$$

Where, $u$ represents the deviation from the theoretical cost function due to inefficiency and $v$ is the estimation random error. Due to its flexibility, we apply a translog as the function form $(f)$ (in order to compare the results with the existing studies, in Appendix B we provide the results when using a Cobb-Douglas function). In order to evaluate the impact of ownership on the ANSP costs, we use two approaches. Ownership structure (and environmental variables) can influence (i) the cost function or (ii) the units' efficiency. In the former case, the environmental variables are included in the right-hand side of the equation hence following the standard stochastic frontier approach considering I ANSPs $(i=1, \ldots, I)$ and $T$ periods $(t=1, \ldots, T)$ which can be defined for the variable cost function as:

$$
V C_{i t}=f\left(Y_{i t}, W_{i t}, K_{i t} ; \beta\right)+\sum_{j}^{M} \theta_{j} z_{j, i t}+\tau_{1} t_{i t}+\tau_{2} t_{i t}^{2}+v_{i t}+u_{i t}
$$

and for the total cost function as:

$$
T C_{i t}=f\left(Y_{i t}, W_{i t} ; \beta\right)+\sum_{j}^{M} \theta_{j} z_{j, i t}+\tau_{1} t_{i t}+\tau_{2} t_{i t}^{2}+v_{i t}+u_{i t}
$$

Where, the output (Y), the set of input prices (W) and the capital (K) are considered in the function parameterisation, the environmental variables $\left(z_{j}\right)$ are considered in a log linear fashion while the time trend $t$ in a neutral non-linear way. The term $v_{i t}$ is the common error component independently and identically distributed as $N\left(0, \sigma_{v}^{2}\right)$, while $u_{i t}$ is the time varying inefficiency term estimated as $u_{i t}=\exp (\eta(t-T)) * u_{i}$ (Battese and Coelli, 1992) with $u_{i} \sim \operatorname{Exp}(\lambda)$. When the ownership structures are deemed to influence the units' efficiency, it is possible to implement the approach proposed by Koop et al. (1997). More precisely, it is possible to estimate equations (4a) and (4b) by assuming the covariates $\left(z_{j}\right)$ to affect the posterior mean of the inefficiency term distribution as:

$$
u_{i} \sim \operatorname{Exp}\left(\exp \left\{\sum_{j}^{M} \delta_{j} z_{j, i} \cdot\right\}\right)
$$


Estimating equations ( $4 a$ and $4 b$ ) it is possible to analyse the impact of the ownership on the ANSP cost structures. Estimating the inefficiencies as in equation (5), it is possible to analyse the direct impact of ownership on the cost efficiencies (i.e. including the ownership variables in the inefficiency distribution). ${ }^{2}$ Both in the case of equations (4) and (5), the environmental variables do not interact with the inputs or the time. Therefore, frontier shape, input-output and substitution elasticities are not influenced by the environment. In order to be consistent with the economics theory and to provide reliable estimations, the cost function needs to satisfy the property of non-negativity in costs, homogeneity, monotonicity in output and input prices and concavity. The homogeneity condition can be implemented by simply normalising the input prices and the variable costs by one of the input prices, while monotonicity and concavity are more difficult to impose. The most common approach is to estimate the model without imposing these two conditions only assessing the severity of the constraints violations; however, this practice could lead to distorted parameter estimates (e.g. as shown in Chua et al., 2005). Different viable implementation alternatives are indicated in literature (some examples include Ryan and Wales, 1998 and 2000), in our work we use the accept/reject algorithm proposed by Terrell (1996). The method locally imposes monotonicity and concavity by assigning zero weights to the parameter vectors leading to monotonicity and concavity violations. The estimations of equations (4) and (5) implement the Terrell algorithm by employing a Markov Chain Monte Carlo (MCMC) method (Gibbs Sampler) in a Bayesian framework. Indeed, one of the advantages of applying Bayesian estimation for the stochastic frontier methods is the easy incorporation of regularity conditions. Other advantages of stochastic Bayesian approach comprehend the exact inference on the inefficiencies and the formal treatment of parameters and model uncertainties (van den Broeck et al.,1994 and Coelli et al., 2006, Griffin and Steel, 2007). ${ }^{3}$

\section{Data}

Data are extracted from EUROCONTROL annual ATM Cost-Effectiveness (ACE) Benchmarking reports, which consist of technical and economic information provided by each ANSP. The data used within this study includes civil air traffic management/ communications, navigation and surveillance (ATM/CNS) related gate-to-gate costs. The datasets excludes costs, inputs and outputs associated with ATM service provision for military aviation. The data set includes information for 37 European ANSPs for 2006 to $2014 .{ }^{4}$ Data prior to 2006 are not consistent in the traffic complexity measure and therefore are not considered.

\footnotetext{
${ }^{2}$ We estimated the function applying different efficiency distributions (i.e. normal distribution and truncated normal distribution). In our case, the exponential distribution was the best performing, specifically when considering estimations convergence.

${ }^{3}$ For a formal description of the Bayesian estimation process we refer the reader to van den Broeck et al., (1994) and Koop et al. (1997). With respect to the technical implementation of the Terrell algorithm we reference Griffin and Steel (2007).

${ }^{4}$ Data for Armenia ANSP are available from 2009.
} 
As total costs (TC) we use the ATM/CNS provision costs, while as variable costs (VC) the ATM/CNS provision costs less the depreciation costs and the cost of capital. Using data related to ATM/CNS, we focus our study on ANSPs regulated activities. We consider a unique output (Y) computed as the composite flight hours controlled. This measure is a weighted sum of en-route flight hours controlled and the number of instrumental flight rule airport movements controlled and it is commonly used in ANSPs benchmarking. The input price vector includes the price for air traffic controllers ATCOs (W1), the price for non-operational staff (W2), and the price for non-staff operating inputs (W3). W1 and $\mathrm{W} 2$ are computed as the relative costs divided by the relative full time equivalent (FTE) numbers. The non-staff operating input is a "catch all costs" category, including energy, spare parts, communications, contracted services etc., hence as W3, we consider the consumer price index at country level sourced from the World Bank. As in the previous literature (e.g. Scotti and Volta 2017, Oum and Yu 1998), the inclusion of a price index captures the standard inputs price heterogeneities between countries. When estimating the variable cost function (equation 3a), as quasi-fixed capital (K) we use the capital net book value for the fixed assets in operation. $\mathrm{K}$ considers capital inputs used in ATM/CNS such as buildings, controller working environment and positions, ATM equipment, and CNS infrastructure. ${ }^{5}$ In the total cost function (equation $3 b$ ) we compute the capital related input price (W4) as in Competition Economists Group (2011) (i.e. following the suggestion of the EUROCONTROL performance review unit). More precisely, W4 is computed as the sum of depreciation costs and the cost of capital divided by the net book value in operation adjusted by the annual producer price index. ${ }^{6}$

We include a vector of exogenous variables developed by EUROCONTROL describing the total area controlled by the ANSP (Z1), the airspace complexity (Z2) and the traffic variability (Z3). The area controlled captures the network characteristics and can be used to compute economies of scale. The airspace complexity (composed by the adjusted density and the structural complexity) and the traffic variability (computed as traffic at the peak week divided by the traffic in the average week) are used to control traffic characteristics. ${ }^{7}$ Finally, a set of dummy variables representing the ownership structures of the ANSPs are added to study the effect of ownership; private (D1), commercialised (omitted), and public (D3). Ownership structures are drawn from the ACE Benchmarking reports. D1 and D3 are firstly included as cost shifters (as per Equation 3) and then as efficiency modifiers (as per Equation 4). Cyprus (DCAC), France (DSNA), Greece (HCCA) and Turkey (DHMI) are considered as ANSPs operating under public ownership (i.e. state bodies or autonomous state companies) while Maastricht Upper Area Control (MUAC), Switzerland (Skyguide) and The United Kingdom (NATS)

\footnotetext{
${ }^{5}$ The net book value provided by EUROCONTROL is reported by each of the ANPSs and could be affected by inconsistencies due to the different depreciation rules between countries.

${ }^{6}$ In our study we used the producer price index sourced from Eurostat.

${ }^{7}$ Detailed information regarding the metrics can be found in the report "complexity metrics for ANSP benchmarking analysis" (2006).
} 
are considered as private (international or partly private companies). All the remaining European ANSPs are deemed as commercialised. The complete list of ANSPs considered and their relative ownership form is shown in Appendix A.

Monetary values (i.e. VC, W1, W2, W4 and K) are adjusted by purchasing power parity (PPP) indicators to enable comparisons across countries. In total we consider a slightly unbalanced dataset of 330 observations over nine years. Table 1 shows the descriptive statistics for the sample in the last year under observation (2014).

Table 1 - Descriptive statistics (2014 data)

\begin{tabular}{|c|c|c|c|c|}
\hline Variable & Mean & SD & Maximum & Minimum \\
\hline VC - Variable Costs $(, 000 €)$ & 196,011 & 233,960 & 954,784 & 11,573 \\
\hline TC - Total Costs $(, 000 €)$ & 240,934 & 289,069 & $1,100,925$ & 16,661 \\
\hline W1 - Price of ATCOs staff $(, 000 €)$ & 152 & 57 & 268 & 32 \\
\hline W2 - Price of non-ATCOs staff(,000 $€)$ & 79 & 32 & 171 & 16 \\
\hline W3 - Materials Price (index) & 110 & 7 & 136 & 99 \\
\hline W4 - Price of Capital (index) & 0.35 & 0.21 & 1.09 & 0.11 \\
\hline Y - Composite flight hours (,000) & 503,736 & 621 & $2,639,898$ & 18,273 \\
\hline K - Capital $(, 000 €)$ & 207,799 & 269,539 & $1,036,882$ & 15,688 \\
\hline Z1 - Area controlled $\left(\mathrm{km}^{\wedge} 2\right)$ & 354,278 & 431,946 & $2,190,000$ & 20,400 \\
\hline Z2 - Airspace Complexity (index) & 5.02 & 3.28 & 12.30 & 0.81 \\
\hline Z3 - Traffic Variability (index) & 1.31 & 0.16 & 1.71 & 1.11 \\
\hline
\end{tabular}

Figure 1a presents the change of the average variable cost (VC), total cost (TC) and composite flight hours (Y), with respect to 2006. Both VC and TC show a similar trend, constantly increasing during the period. Average variable costs increased from $167 \mathrm{M}$ to $196 \mathrm{M}(+16 \%)$ while total costs increased from $212 \mathrm{M}$ to $240 \mathrm{M}(+13 \%)$. The two cost variables show a similar pattern and magnitude with the composite flight hours for 2007 and 2008. However, with the end of the financial crisis the cost variables had a stronger growth while the average output only slightly increased reaching a $+5 \%$ rise at the end of the period, below the pre-crisis level. Figure $1 \mathrm{~b}$ presents the changes in prices (W1, W2, W3 and W4) and capital (K). Generally, the five variables increased since 2006, with exception of capital price and capital stock remaining similar over the period lower than the increase seen in price of ATCOs (W1: +33\%) and price of non-ATCO staff and material prices (W2, W3: +25). W4 shows a $10 \%$ increase over the period with a significant fall from 2011 to 2012, as a result of relatively big increases in NBV values in some ANSPs (NBV appears in the denominator of W4 equation). ${ }^{8}$ However, due to the relatively small magnitude of these NBV this effect is negligible when analysing

\footnotetext{
${ }^{8}$ For examples, the NBV of Albania changes from $29 \mathrm{M}$ to $40 \mathrm{M}$ of euros, the NBV of Armenia from $5 \mathrm{M}$ to $9 \mathrm{M}$, while in Estonia from $10 \mathrm{M}$ to $18 \mathrm{M}$.
} 
the capital variable (K). Finally, Figure 1c presents the average increase of composite hours in relation to the average change in traffic characteristics (i.e. complexity and variability). Generally, variability index shows a small change during the period $(+4 \%)$ in line with the change in composite flight hours $(+5 \%)$. The average complexity shows a greater increase during the period $(+18 \%)$.

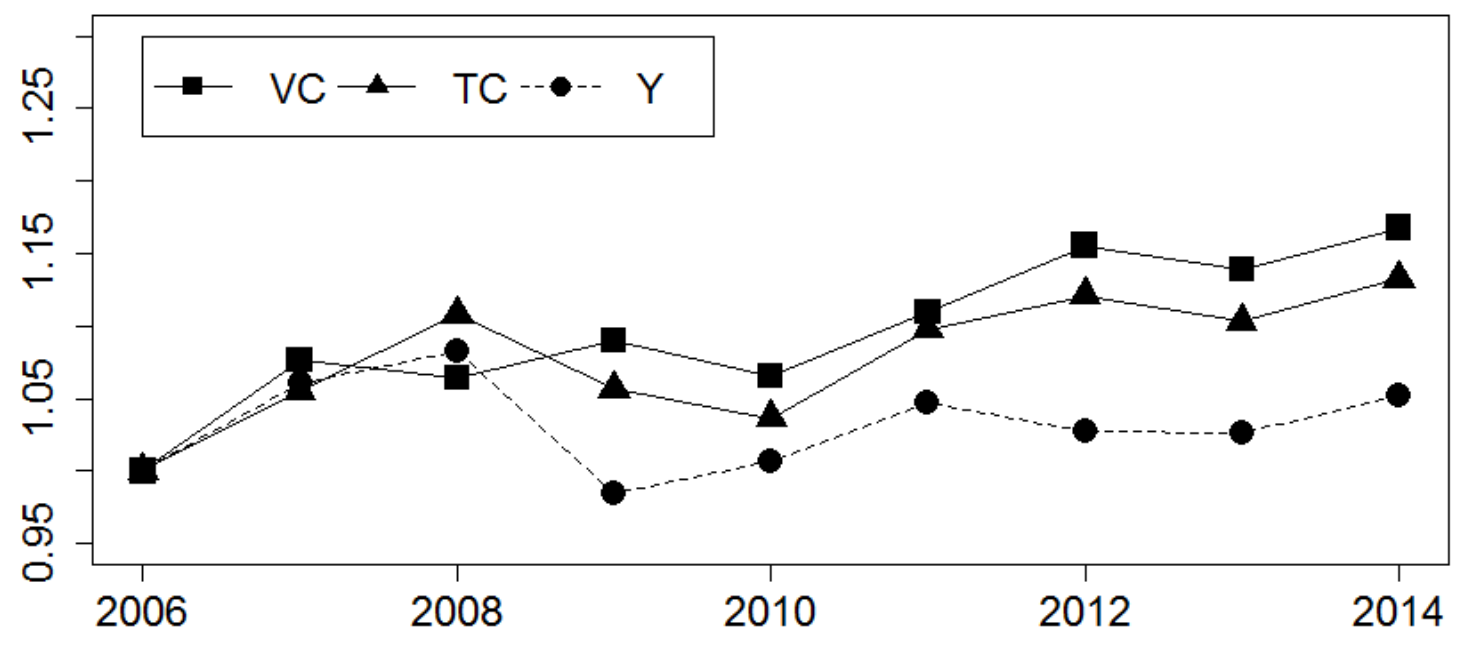

Figure 1a - Average changes in VC, TC and output with respect to 2006

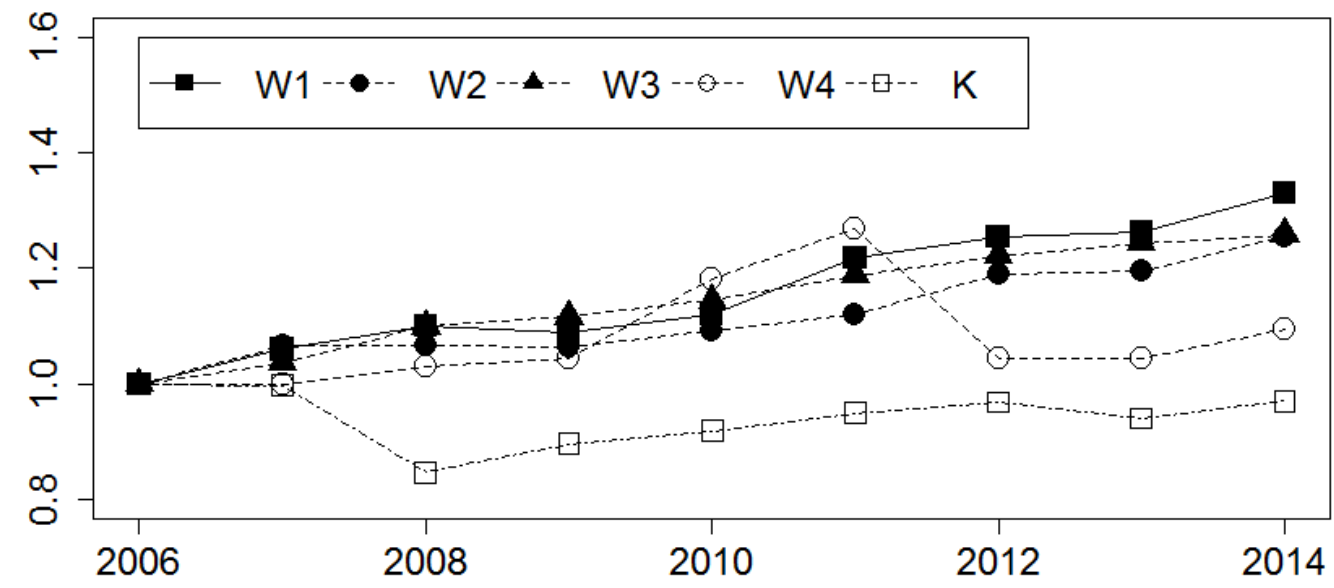

Figure $1 \mathrm{~b}$ - Average changes in prices and capital stock with respect to 2006 


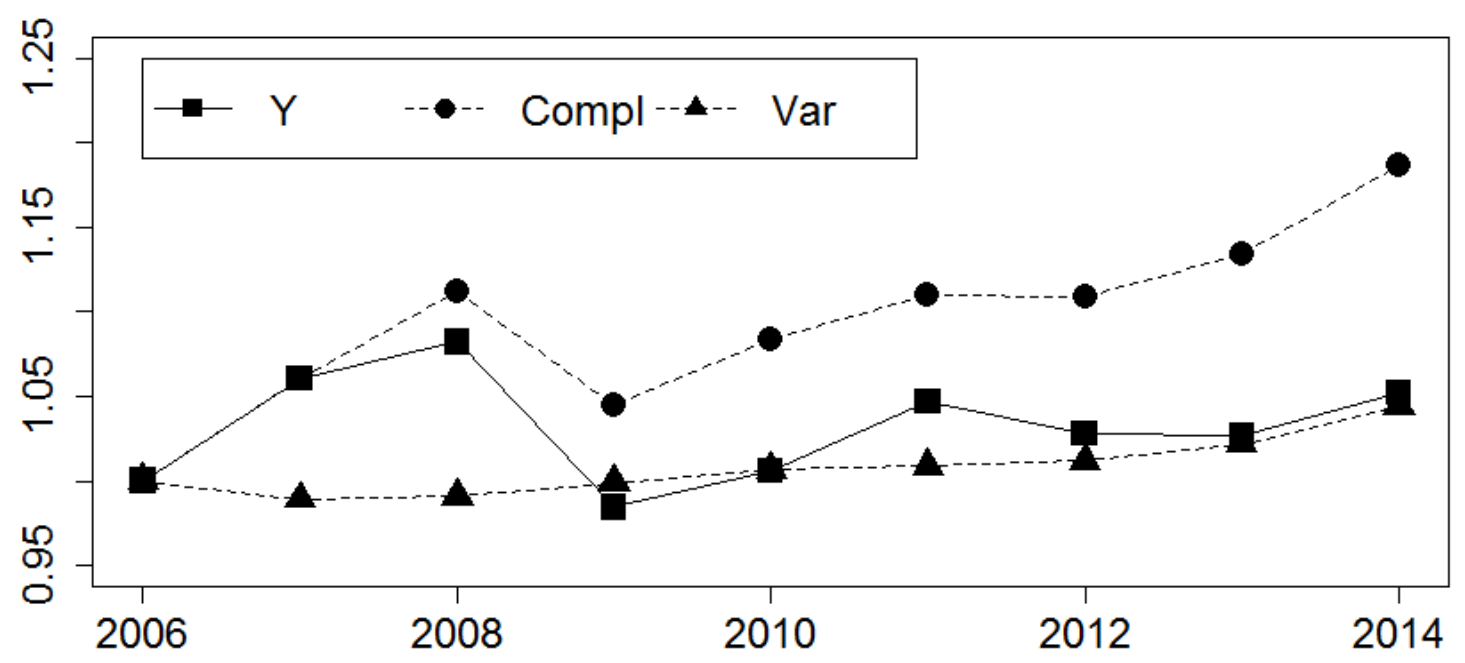

Figure 1c - Average changes in Y, Complexity and Variability with respect to 2006

\section{Results}

We estimate specifications 4 and 5 (i.e. ownership variables considered in the cost structure and ownership variables considered in the inefficiency distribution) to the variable cost and total cost functions. Results are provided for the translog functional forms (Appendix B shows the results when using a Cobb-Douglas function). All the estimates are obtained using a Bayesian approach. Prior distributions for the parameters are introduced following Griffin and Steel (2004) and (2007). Results are based on 100,000 draws with a thinning to every fifth draw after a burn-in of 50,000 iterations. The non-staff operating price (W3) is used as a normalisation variable to implement homogeneity. All of the variables (except for the dummies and the time trend) are mean corrected prior to the estimation, thus the elasticities of cost with respect to the factor prices are equivalent to shares in costs at the average observation.

Table 2 shows the variable cost function estimated parameters (i.e. posterior mean), the standard deviation and the 95\% confidence interval for the two specifications (specification $4 \mathrm{a}$ and specification 5, respectively). The estimates for an additional 50,000 draws (Appendix C) and the posterior densities (obtainable upon request to the authors) show the estimations convergence.

Table 2 - Variable cost function (VC) estimates

\begin{tabular}{|c|cccc|cccc|}
\cline { 2 - 8 } \multicolumn{1}{c|}{} & \multicolumn{4}{c|}{ Model 4VC } & \multicolumn{4}{c|}{ Model 5VC } \\
\hline Variable & Mean & sd & $\mathbf{2 . 5 0 \%}$ & $\mathbf{9 7 . 5 0 \%}$ & Mean & sd & $\mathbf{2 . 5 0 \%}$ & $\mathbf{9 7 . 5 0 \%}$ \\
Intercept & -1.286 & 0.138 & -1.586 & -1.272 & -1.166 & 0.097 & -1.379 & -0.991 \\
W1 - ATCOs & 0.364 & 0.033 & 0.300 & 0.364 & 0.372 & 0.033 & 0.307 & 0.438
\end{tabular}




\begin{tabular}{|c|c|c|c|c|c|c|c|c|}
\hline W2 - Non-ATCOs & 0.420 & 0.032 & 0.359 & 0.419 & 0.410 & 0.032 & 0.348 & 0.472 \\
\hline Y - Output & 0.259 & 0.064 & 0.131 & 0.261 & 0.254 & 0.062 & 0.129 & 0.373 \\
\hline K - Capital & 0.045 & 0.017 & 0.013 & 0.045 & 0.036 & 0.016 & 0.004 & 0.068 \\
\hline $\mathrm{W} 1 * \mathrm{~W} 1$ & 0.180 & 0.049 & 0.084 & 0.180 & 0.198 & 0.050 & 0.100 & 0.296 \\
\hline $\mathrm{W} 2 * \mathrm{~W} 2$ & 0.144 & 0.026 & 0.092 & 0.144 & 0.139 & 0.027 & 0.086 & 0.191 \\
\hline $\mathbf{Y} * \mathbf{Y}$ & 0.007 & 0.024 & -0.040 & 0.007 & -0.004 & 0.022 & -0.046 & 0.040 \\
\hline $\mathbf{K} * \mathbf{K}$ & -0.003 & 0.011 & -0.024 & -0.003 & -0.005 & 0.011 & -0.026 & 0.016 \\
\hline $\mathrm{W} 1 * \mathrm{~W} 2$ & -0.379 & 0.078 & -0.532 & -0.379 & -0.380 & 0.077 & -0.529 & -0.229 \\
\hline $\mathbf{W} 1 * \mathbf{Y}$ & 0.065 & 0.040 & -0.010 & 0.064 & 0.064 & 0.040 & -0.017 & 0.140 \\
\hline $\mathbf{W} 1 * \mathbf{K}$ & 0.063 & 0.039 & -0.015 & 0.063 & 0.054 & 0.040 & -0.022 & 0.134 \\
\hline $\mathrm{W} 2 * \mathrm{Y}$ & 0.001 & 0.047 & -0.091 & 0.002 & -0.011 & 0.046 & -0.100 & 0.080 \\
\hline $\mathbf{W} 2 * \mathbf{K}$ & -0.050 & 0.039 & -0.128 & -0.050 & -0.033 & 0.040 & -0.111 & 0.045 \\
\hline $\mathbf{Y * K}$ & -0.001 & 0.019 & -0.036 & -0.001 & -0.006 & 0.018 & -0.041 & 0.030 \\
\hline $\mathrm{t}$ - Time & 0.021 & 0.009 & 0.005 & 0.021 & 0.008 & 0.007 & -0.006 & 0.023 \\
\hline$t * t$ & -0.002 & 0.001 & -0.003 & -0.002 & -0.002 & 0.001 & -0.003 & 0.000 \\
\hline Z1 - Area & 0.270 & 0.116 & -0.050 & 0.289 & 0.358 & 0.096 & 0.174 & 0.560 \\
\hline Z2 - Complexity & 0.010 & 0.024 & -0.037 & 0.010 & 0.008 & 0.025 & -0.041 & 0.058 \\
\hline Z3 - Variability & 0.228 & 0.193 & -0.152 & 0.227 & 0.140 & 0.196 & -0.250 & 0.531 \\
\hline D1 - Private & 0.352 & 0.267 & -0.279 & 0.367 & & & & \\
\hline D2 - Public & 0.314 & 0.176 & -0.080 & 0.328 & & & & \\
\hline Intercept & & & & & -0.134 & 0.198 & -0.536 & 0.239 \\
\hline D1 - Private & & & & & -0.304 & 0.656 & -1.749 & 0.825 \\
\hline D2 - Public & & & & & -0.318 & 0.572 & -1.548 & 0.695 \\
\hline Eta $(\eta)$ & -0.009 & 0.003 & -0.016 & -0.003 & & & & \\
\hline Sigma sq. u & 0.005 & 0.000 & 0.004 & 0.006 & 0.005 & 0.000 & 0.004 & 0.006 \\
\hline Lambda9 & 0.936 & 0.180 & 0.624 & 1.325 & 0.892 & 0.175 & 0.585 & 1.269 \\
\hline DIC & \multicolumn{4}{|c|}{4725} & & 4732 & & \\
\hline
\end{tabular}

The two models show a relatively low lambda hence a relatively high inefficiency variance. This implies that a large part of the deviations from the cost minimising function is due to inefficiency and that the choice of a stochastic frontier approach is correct. The average estimated efficiency for the industry is relatively low, 38\% - for Model 4VC, 37\% - for Model 5VC. Comparing the two models, the estimates are similar and showing the expected signs with most of the cross and second order estimated coefficients being statistically significant. When computing the deviance information criterion (DIC), Model 4VC shows a slightly lower DIC value being the best-fit model for the ANSPs data. The differences between the results are mainly explained by the way in which the ownership variables are introduced in the analysis.

\footnotetext{
${ }^{9}$ In Model 5VC, Lambda 2 and Lambda 3 (i.e. D1=1 and D2=1, respectively) are 0.775 and 0.732.
} 
Analysing Model 4VC results, at the sample mean the ATCOs labour (W1) accounts for $36 \%$ of variable costs, non-operational labour (W2) accounts for 42\%, and materials (W3) represents the remaining 22\%. Similar results can be depicted in Model 5VC with W1 accounting for $37 \%$ of variable costs, $\mathrm{W} 2$ for $41 \%$, and $\mathrm{W} 3$ for $22 \%$. An increase of $1 \%$ of the output (Y) implies an increase of around $0.26 \%$ of variable costs in both models. The time parameters $(t$ and $t * t)$ both show weak significance, suggesting that the variable costs are possibly increasing at a decreasing rate during the period analysed, ceteris paribus. Moreover, the results suggest that the traffic characteristics (Z2 Complexity and Z3 - Variability) are positive albeit not statistically significant while the Area (Z1) has a positive and significant impact on variable costs. Model $4 \mathrm{VC}$ provides a negative eta $(\eta)$ highlighting that ANSPs have slightly improved their variable cost-efficiencies over the period analysed. The ownership variables are not significant neither in Model 4VC nor in Model 5VC. Our results show that the ownership structure is not impacting the European ANSP variable cost function $(4 \mathrm{VC})$ and the cost-efficiencies (5VC). Finally, the Bayesian framework allows the evaluation of the kernel density estimates of the posterior distributions of the economies of scale at the sample mean. Economies of scale are computed as $1 /\left[\varepsilon_{\mathrm{Y}}+\varepsilon_{\mathrm{Z} 1}\right]$, where $\varepsilon_{\mathrm{Y}}$ is the output elasticity and $\varepsilon_{\mathrm{Z} 1}$ is the controlled area elasticity, respectively (Figure 2). Both models show the presence of economies of scale with the estimates significantly distributed above the unit, on average an increase of $1 \%$ in the composite flight hours and area controlled may lead to a less than proportional estimated increase in variable costs of $0.60 \%$ (Model 4VC) and $0.54 \%$ (Model 5VC).

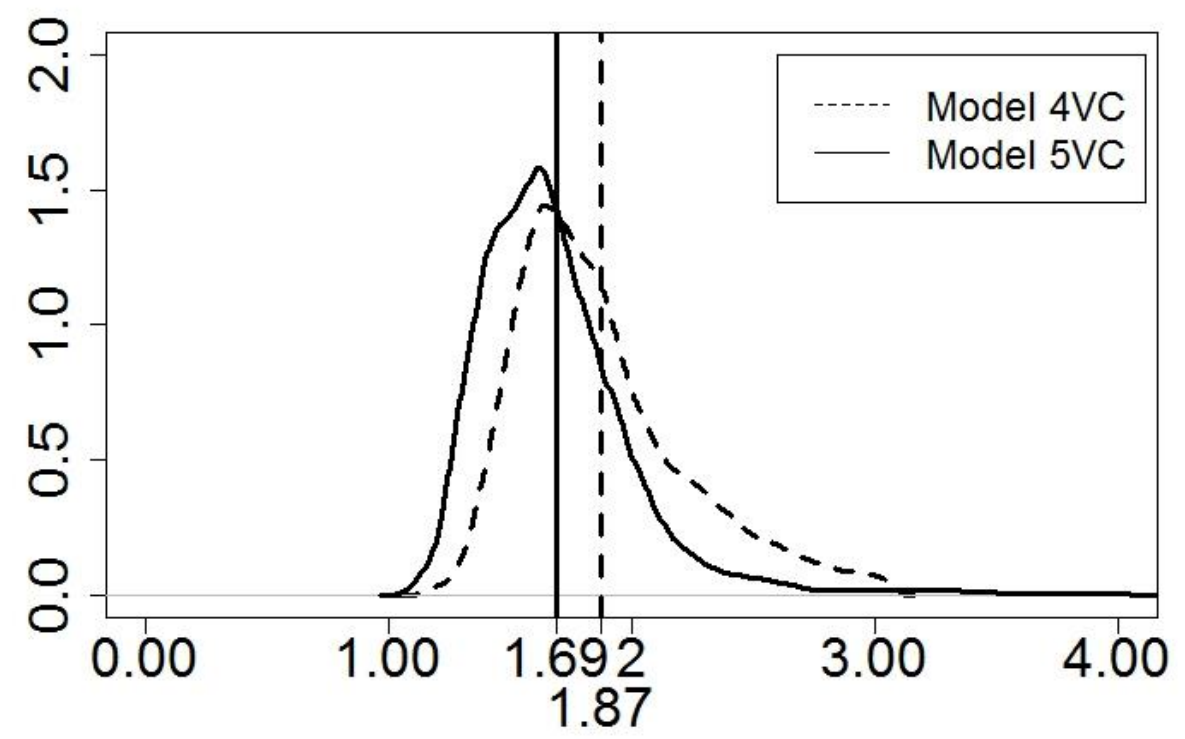

\begin{tabular}{|c|c|c|c|c|}
\hline & Mean & sd & $\mathbf{2 . 5 0 \%}$ & $\mathbf{9 7 . 5 0 \%}$ \\
\hline Scale - Model 4VC & 1.871 & 0.356 & 1.374 & 2.776 \\
\hline Scale - Model 5VC & 1.691 & 0.349 & 1.245 & 2.547 \\
\hline
\end{tabular}




\section{Figure 2 - Kernel density of estimated economies of scale (variable cost models)}

Table 3 shows the total cost function estimated parameters (i.e. posterior mean), the standard deviation and the $95 \%$ confidence interval for the two specifications (equation $4 \mathrm{~b}$ and equation 5 , respectively). For consistency, as for the previous estimations the following was considered; i) we use the same prior distributions for the parameters, ii) estimates are based on 100,000 iterations with a thinning of 5 with a burn-in of 50,000 iterations, and iii) we use W3 as normalisation variable.

Table 3 - Total cost function (TC) estimates

\begin{tabular}{|c|c|c|c|c|c|c|c|c|}
\hline \multirow[b]{2}{*}{ Variable } & \multicolumn{4}{|c|}{ Model 4TC } & \multicolumn{4}{|c|}{ Model 5TC } \\
\hline & Mean & sd & $2.50 \%$ & $\mathbf{9 7 . 5 0 \%}$ & Mean & sd & $2.50 \%$ & $97.50 \%$ \\
\hline Intercept & -1.351 & 0.107 & -1.564 & -1.139 & -1.28 & 0.103 & -1.487 & -1.083 \\
\hline W1 - ATCOs & 0.384 & 0.033 & 0.319 & 0.449 & 0.389 & 0.034 & 0.321 & 0.456 \\
\hline W2 - Non-ATCOs & 0.361 & 0.032 & 0.297 & 0.423 & 0.358 & 0.032 & 0.295 & 0.421 \\
\hline W4 - Capital price & 0.181 & 0.062 & 0.063 & 0.305 & 0.200 & 0.063 & 0.076 & 0.322 \\
\hline Y - Output & 0.045 & 0.018 & 0.010 & 0.079 & 0.046 & 0.017 & 0.012 & 0.08 \\
\hline $\mathrm{W} 1 * \mathrm{~W} 1$ & 0.063 & 0.049 & -0.033 & 0.16 & 0.067 & 0.051 & -0.031 & 0.168 \\
\hline $\mathrm{W} 2 * \mathrm{~W} 2$ & 0.125 & 0.03 & 0.066 & 0.185 & 0.123 & 0.031 & 0.062 & 0.184 \\
\hline W4*W4 & -0.011 & 0.019 & -0.047 & 0.026 & -0.019 & 0.018 & -0.053 & 0.016 \\
\hline $\mathbf{Y} * \mathbf{Y}$ & 0.027 & 0.007 & 0.014 & 0.041 & 0.027 & 0.007 & 0.014 & 0.040 \\
\hline $\mathrm{W} 1 * \mathrm{~W} 2$ & -0.243 & 0.077 & -0.394 & -0.092 & -0.247 & 0.081 & -0.405 & -0.091 \\
\hline $\mathrm{W} 1 * \mathrm{~W} 4$ & 0.135 & 0.034 & 0.068 & 0.199 & 0.136 & 0.033 & 0.072 & 0.203 \\
\hline $\mathbf{W} 1 * \mathbf{Y}$ & -0.055 & 0.042 & -0.138 & 0.027 & -0.066 & 0.042 & -0.149 & 0.017 \\
\hline $\mathrm{W} 2 * \mathrm{~W} 4$ & -0.065 & 0.033 & -0.131 & -0.001 & -0.061 & 0.033 & -0.127 & 0.004 \\
\hline $\mathbf{W} 2 * \mathbf{Y}$ & -0.006 & 0.03 & -0.064 & 0.052 & -0.005 & 0.03 & -0.064 & 0.054 \\
\hline $\mathrm{W} 4 * \mathbf{Y}$ & 0.041 & 0.015 & 0.011 & 0.07 & 0.041 & 0.015 & 0.011 & 0.070 \\
\hline t - Time & 0.000 & 0.009 & -0.018 & 0.017 & -0.006 & 0.007 & -0.021 & 0.008 \\
\hline$t * t$ & -0.001 & 0.001 & -0.002 & 0.001 & -0.001 & 0.001 & -0.002 & 0.001 \\
\hline Z1 - Area & 0.305 & 0.097 & 0.145 & 0.52 & 0.273 & 0.1 & 0.079 & 0.488 \\
\hline Z2 - Complexity & 0.028 & 0.024 & -0.019 & 0.074 & 0.026 & 0.024 & -0.02 & 0.073 \\
\hline Z3 - Variability & 0.109 & 0.189 & -0.258 & 0.479 & 0.117 & 0.189 & -0.255 & 0.489 \\
\hline D1 - Private & 0.243 & 0.497 & -1.226 & 0.814 & & & & \\
\hline D2 - Public & 0.215 & 0.394 & -1.049 & 0.594 & & & & \\
\hline Intercept & & & & & -0.245 & 0.196 & -0.641 & 0.126 \\
\hline D1 - Private & & & & & -0.378 & 0.660 & -1.824 & 0.756 \\
\hline D2 - Public & & & & & -0.424 & 0.571 & -1.647 & 0.590 \\
\hline Eta $(\eta)$ & -0.003 & 0.003 & -0.008 & 0.002 & & & & \\
\hline Sigma sq. u & 0.005 & 0.000 & 0.004 & 0.006 & 0.005 & 0.000 & 0.000 & 0.004 \\
\hline Lambda $^{10}$ & 0.782 & 0.140 & 0.535 & 1.083 & 0.798 & 0.155 & 0.527 & 1.134 \\
\hline DIC & & & 717 & & & & 4719 & \\
\hline
\end{tabular}

${ }^{10}$ In Model 5TC, Lambda 2 and Lambda 3 (i.e. D1=1 and D2=1, respectively) are 0.644 and 0.588. 
Most of the comments of table 2 are valid for the total cost function results. The models show a relatively low lambda hence a moderately high inefficiency variance, the estimates are similar and show the expected signs. The average estimated efficiency for the industry is still relatively low, around $33 \%$ for both the models. In Model 4TC, at the sample mean the ATCOs labour (W1) accounts for 38\% of total costs, non-operational labour (W2) accounts for 36\%, capital (W4) accounts for $18 \%$ and materials (W3) represents the remaining $8 \%$. Similar results can be depicted in Model 5TC with the only small difference in W4 (20\%) and consequently in W3 (6\%). Shares in costs are similar to those obtained by the Competition Analysis Group (2012) (our estimates are slightly higher in the labour variable) and substantially different from the estimates of NERA (2006) (mainly in the non-ATCOs share which is accounting for almost $50 \%$ of total costs). ${ }^{11}$ An increase of $1 \%$ of the output (Y) implies an increase of around $0.05 \%$ of total costs in both models 4TC and 5TC (almost five times less than the impact on variable costs). The time parameters ( $t$ and $t * t)$ show weak significance, suggesting that the total costs are not changing during the period analysed, ceteris paribus. The estimate of eta $(\eta)$ shows a non significant improvement in the total cost efficiencies. As for the variable cost estimates, complexity (Z2) and variability (Z3) are not significant, while an increase in the area controlled (Z1) increases the total costs (we notice that these results are shared with previous studies, despite the differences in period analysed). A possible explanation for complexity and variability not baring significance may result from these two variables by nature concerning themselves with only en-route stages of flight, whereas this study concerns itself with gate-to-gate costs. Even when considering long-term cost functions, the ownership variables are not significant either as determinants of the cost structure or as cost-efficiency explanatories. Figure 3 shows the kernel distribution for the posterior densities of the economies of scale at the sample mean. Results show the average ANSP lying on the increasing economies of scales part of the technology, an increase of $1 \%$ in composite flight hours and Area controlled may lead to a less than proportional increase of $0.46 \%$ (Model 4TC) and $0.48 \%$ (Model 5TC) in total costs.

\footnotetext{
${ }^{11}$ The estimates differ in the methodological approach, the functional form and, most importantly, in the years analysed.
} 


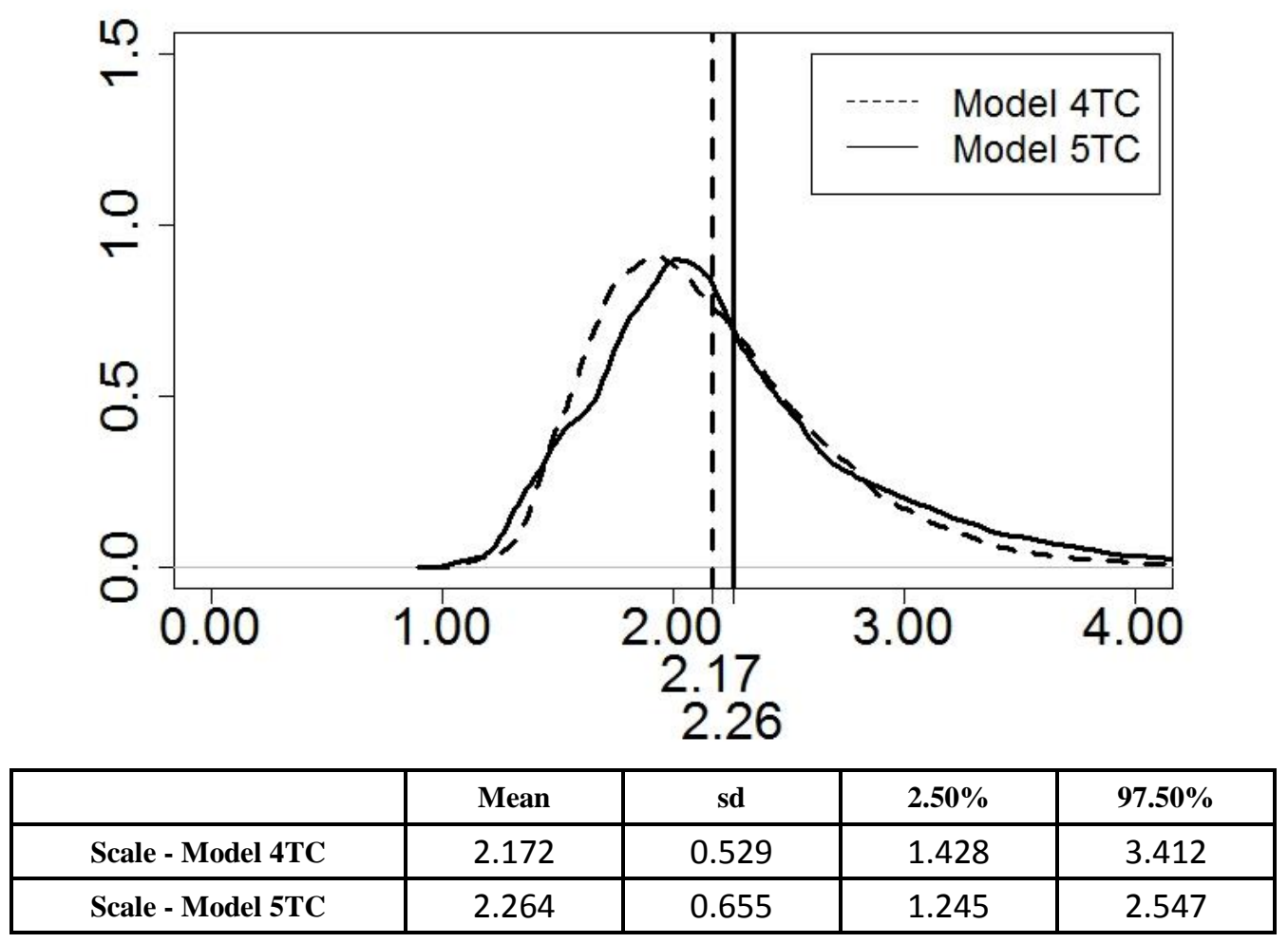

Figure 3 - Kernel density of estimated economies of scale (total cost models)

\section{5) Discussion}

The estimated models show that the ownership structures do not impact neither the cost structure nor the cost efficiency of European ANSPs. These results are in line with the work of Vickers and Yarrow (1991), which showed that regulation is more important than privatisation to achieve efficiencies within a monopolistic context. In the specific case of ANSPS, there are numerous reasons which provide possible explanations to these findings. Generally, all ANSPs must operate in accordance with common regulations and frameworks such as those determined by EURCONTROL. Given the environment within which the European ANSPs must operate such as the SES (which already looks to ensure cost-efficiencies despite the ownership structure), it is arguably difficult for private sector employees to further enhance the ANSPs' cost efficiencies or in general to reduce costs. Irrespective of ownership, all ANSPs must ensure safety as the top priority, therefore they are strictly regulated and cannot reduce head count of ATCOs or technology levels (the two most expensive factors). Another possible explanation is that whilst having secured a degree of autonomy from their respective governments, behaviours are culturally driven and despite ANSPs being commercialised, they often still function in practical terms as a public entity (i.e. 100\% government owned and operating under government control). For example, in some countries the staff in the ANSP often switch between the ANSP and the regulator (e.g. Romania), whilst the CEO of the Irish ANSP, IAA, is both head of the Civil Aviation Authority and the ANSP simultaneously. This could therefore create difficulties in 
ascertaining the direct influence of ownership and institutional structures on costs and costefficiencies. Finally, around $81 \%$ of the ANSPs included within the study were categorised as commercialised. Given that Commercialised ANSPs are government owned but have a level of autonomy, there is not a clear definition between the outcomes of differing ownership models as commercialised is a sort of amalgamation of different structures. Whilst commercialised ANSPs are more remote from the government than those falling within the 'public' classification, they can still benefit from many of the advantages of being government owned, such as the ability to utilise cheaper government resources for procurement and facilities whilst also being open to the ability to utilise private sector contractors. The unbalanced number of observations deemed as commercialised may, as well, create a problem in statistically identifying differences. However, we note that if a real difference exists, the coefficients should reflect it at least with a low significance level.

Another significant indication obtained from the estimations is that the average European ANSP is lying on the increasing return to scale part of the technology. Our results suggest that the industry has the possibility of decreasing costs by agglomerating the ANSPs. When considering the capital as a freely available input, the economies of scale are notably bigger than the ones estimated in a fixedinput environment. Air traffic controllers, support staff and the composite flight hours (and the relative costs) are related to each other through safety regulations. When considering variable costs, economies of scale are therefore limited given the ATCOs safety constraint in managing traffic volumes. However, this relationship between factors does not hold when considering buildings, ATM equipment and Communication and Navigation Surveillance infrastructures as freely available inputs. Increasing the volume controlled (e.g. by agglomerating the ANSPs) would exploit the large economies of scale estimated by the total cost functions. These results have a policy implication supporting the initiative of the Single European Sky (SES). Indeed, a major component of the initiative is the notion of functional airspace blocks (FAB), which are intended to aggregate several providers into larger entities which are expected to handle air traffic as if they were a single ANSP. However, despite nine defined FAB entities (regulation No. 549/2004 amended in regulation (EC) 1070/2009), only two of have been declared established and notified to the European Commission (UK-Ireland and Denmark-Sweden). Finally, it is important to note that the underlying assumptions of the cost function models are i) the entities cost minimising behaviour and ii) the competitive input price markets. Prior to the new ANSPs reform, the ANSPs were operating under a full recovery regulation hence facing weak explicit incentives in minimising their costs. This is evident in the low level of estimated cost efficiencies. However, it is important to remark that our estimates show that inefficiencies are slowly improved over the time despite the implementation of a price cap regulation. Moreover, due to continuous labour disputes (95 strikes totalling 223 days of disruption for between 2010-2015 in Europe, PWC 2015) labour market prices and costs for certain ANSPs may be higher than those in a competitive market (ATCOs gross pay vs national average varies between $+220 \%$ and 
$+1493 \%$, CANSO 2015). These two factors may provide an explanation for the low efficiency scores estimated by the stochastic frontiers. We notice that this situation is shared with all the works dealing with cost efficiency. Indeed, our estimated efficiency averages are in line with the ones provided by NERA (2006) and the Competition analysis group (2012).

\section{Conclusions}

This article has looked to investigate whether the institutional structures of ANSPs have an impact on their relative costs (variable and total) or on their cost-efficiencies. In order to do so, this work applied a cost stochastic frontier approach to a set of 37 European ANSPs for the period 2006-2014. To satisfy the economics regularity conditions we estimated the functions applying Terrell (1996) algorithm within a Bayesian framework. Using the estimated functions, we then analysed the industry elasticities and returns to scale. Our main results have indicated that ownership and institutional structure does not have any influence upon ANSP cost-efficiencies or upon their cost structures. Whilst this study uses data for a seemingly large timeframe, between 2006 and 2014, arguably, the industry is relatively slow at adapting and as such nine years is possibly not a long enough timeframe to discern long-term trends or ascertain the evolution of the industry in regard to the impact that ownership and institutional structure has on cost-efficiency and cost-structure. This is particularly evidenced through some commercialised ANSPs adapting to their new institutional reforms and still behaving as public entities. The creation of boards to manage ANSPs, represent users and acknowledge the government's ultimate responsibilities in regards to ANS delivery is a way in which ANSPs can ensure appropriate distributions of responsibilities enabling a clearer definition between the entity and the government, reducing ambiguity. Moreover, our results show that the air navigation service providers are lying on the increasing part of the technology with the economies of scale greater when capital is considered as a freely available input (i.e. in a total cost function framework). Our results highlight the importance of increasing the average size of the ANSPs in order to decrease the relative costs, hence supporting the agglomeration process proposed in the SES initiative. Future research could extend this study to ANSPs worldwide considering a wider range of ownership structures. However, potential difficulties (partially already present within the European analysis) may be the availability of data due to different accounting rules and exogenous factors measurements (e.g. airspace complexity indices). Moreover, the research agenda may be focused on the non-regulated, commercially driven aspects of the privatised and commercialised ANSPs. Studies on ANSPs profit maximisation behaviours may complete the analysis in regards to the institutional and ownership reform. 


\section{Reference List}

1. Battese, G.E., Coelli, T.J., (1992). Frontier Production Functions, Technical Efficiency and Panel Data. Journal of Productivity Analysis, 3,153-169.

2. Bilotkach, V., Gitto, S., Jovanovic, R., Mueller, J., Pels, E., (2015). Cost-Efficiency Benchmarking of European Air Navigation Service Providers. Transportation Research Part A: Policy and Practice, 77, 50-60.

3. Button, K, Neiva, R., (2014). Economic Efficiency of European Air Traffic Control Systems. Journal of Transport Economics and Policy, 48, 65-80.

4. Button, K., McDougall, G., (2006). Institutional and Structure Changes in Air Navigation Service-Providing Organizations. Journal of Air Transport Management, 12(5), 236-252.

5. CANSO (2015), ATCO Remuneration and HR Metrics Report.

6. Chua, C.L., Kew, H. Yong, J., (2005). Airline code-share alliances and costs: imposing concavity on translog cost function estimation. Review of Industrial Organization 26, 461487.

7. Coelli, T.J., Prasada Rao, D.S., Battese, G.E., (2006). An introduction to efficiency and productivity analysis. Springer Science \& Business Media.

8. Competition Economists Group, (2011). Econometric Cost-Efficiency Benchmarking of Air Navigation Service Providers. Brussels: EUROCONTROL.

9. European Commission, (2010). Press Release 17 December 2010.

10. Eurocontrol (2006). Complexity Metrics for ANSPs Benchmarking analysis. Report available at: http://www.eurocontrol.int/sites/default/files/publication/files/complexity-report.pdf

11. Griffin, J.E., Steel, M.F.J., (2004). Flexible mixture modelling of stochastic frontier frontiers. Technical Report, University of Warwick.

12. Griffin, J.E., Steel, M.F.J., (2007). Bayesian stochastic frontier analysis using WinBUGS. Journal of Productivity Analysis, 27, 163-176.

13. Koop, G., Osiewalski, J., Steel M.F.J., (1997). Bayesian efficiency analysis through individual effects: Hospital cost frontiers. Journal of Econometrics, 76, 77-105.

14. Lewis, I.A., Zolin, R., (2004). The Public to Private Continuum Measure and the Role of Stakeholder Boards as A Proxy for Markets in The Governance of Air Navigation Services: A Comparative Analysis. International Public Management Review, 5(2), 52-77.

15. Majumdar, A., (1995). Commercializing and restructuring air traffic control: A review of the experience and issues involved. Journal of Air Transport Management, 2(2), 111-122.

16. McDougall, G., Roberts, A., (2008). Commercializing air traffic control: Have the reforms worked? Canadian Public Administration, 51(1), 45-69. 
17. Mouchart, M., Simar, L. (2003). Efficiency Analysis of Air Navigation Services Provision(II): Further Insights

18. NERA Economic Consulting, (2006). Cost Benchmarking of Air Navigation Service Providers: A Stochastic Frontier Analysis.

19. Oster, C.V. and Strong, J.S., (2007). Managing the Skies: Public policy, Organisation and Financing of Air Traffic Management. Aldershot: Ashgate Publishing Limited.

20. Oum, T.H., Yu, C., (1998). Cost competitiveness of major airlines: an international comparision. Transportation Research Part A, 32, 407-422.

21. PWC (2016). Economic Impact of Air Traffic Control Strikes in Europe Prepared for A4E Airlines for Europe.

22. Quendt, T., Vignali, C. Kauffman, H., (2007). European Air Navigation Service Providers at The Crossroads. International Journal of Management Cases, 13, 70-282.

23. Ryan, D.L., Wales, T.J., (1998). A simple method for imposing local curvature in some flexible consumer-demand systems. Journal of Business \& Economic Statistics 16, 3, 331338.

24. Ryan, D.L., Wales, T.J., (2000). Imposing local concavity in the translog and generalized leontief cost functions. Economics Letters, 67, 253-260.

25. Scotti, D., Volta, N., (2017). Profitability change in the global airline industry. Transportation Research Part E, 102, 1-12.

26. Terrell, D., (1996). Incorporating monotonicity and concavity conditions in flexible functional forms. Journal of Applied Econometrics, 11, 179-194.

27. van den Broeck, J., Koop. G., Osiewalski, J., Steel, M.F.J., (1994). Stochastic frontier models: a Bayesian perspective. Journal of Econometrics 61, 273-303.

28. Vickers, J., Yarrow, G., (1991), Economic Perspectives on Privatization, Journal of Economic Perspectives, 5, 111-132. 
Appendix A - List of ANSPs considered and their relative ownership status

\begin{tabular}{|c|c|c|c|}
\hline$\#$ & ANSP & Country & Status \\
\hline 1 & Albcontrol & Albania & Commercialised \\
\hline 2 & ARMATS & Armenia & Commercialised \\
\hline 3 & Austro Control & Austria & Commercialised \\
\hline 4 & Belgocontrol & Belgium & Commercialised \\
\hline 5 & BULATSA & Bulgaria & Commercialised \\
\hline 6 & Croatia Control & Croatia & Commercialised \\
\hline 7 & DCAC Cyprus & Cyprus & Public \\
\hline 8 & ANS CR & Czech Republic & Commercialised \\
\hline 9 & NAVIAIR & Denmark & Commercialised \\
\hline 10 & EANS & Estonia & Commercialised \\
\hline 11 & M-NAV & $\mathrm{F}, \mathrm{Y}, \mathrm{R}, \mathrm{Macedonia}$ & Commercialised \\
\hline 12 & Finavia & Finland & Commercialised \\
\hline 13 & DSNA & France & Public \\
\hline 14 & DFS & Germany & Commercialised \\
\hline 15 & HCAA & Greece & Public \\
\hline 16 & HungaroControl & Hungary & Commercialised \\
\hline 17 & IAA & Ireland & Commercialised \\
\hline 18 & ENAV & Italy & Commercialised \\
\hline 19 & LGS & Latvia & Commercialised \\
\hline 20 & Oro Navigacija & Lithuania & Commercialised \\
\hline 21 & MATS & Malta & Commercialised \\
\hline 22 & MoldATSA & Moldova & Commercialised \\
\hline 23 & MUAC & MUAC & Private \\
\hline 24 & LVNL & Netherlands & Commercialised \\
\hline 25 & Avinor (Continental) & Norway & Commercialised \\
\hline 26 & PANSA & Poland & Commercialised \\
\hline 27 & NAV Portugal (Continental) & Portugal & Commercialised \\
\hline 28 & ROMATSA & Romania & Commercialised \\
\hline 29 & SMATSA & Serbia and Montenegro & Commercialised \\
\hline 30 & LPS & Slovak Republic & Commercialised \\
\hline 31 & Slovenia Control & Slovenia & Commercialised \\
\hline 32 & ENAIRE & Spain & Commercialised \\
\hline 33 & LFV & Sweden & Commercialised \\
\hline 34 & Skyguide & Switzerland & Private \\
\hline 35 & DHMI & Turkey & Public \\
\hline 36 & UkSATSE & Ukraine & Commercialised \\
\hline 37 & NATS (Continental) & United Kingdom & Private \\
\hline
\end{tabular}


Appendix B - Cobb-Douglas estimation results based on 100,000 draws with a thinning to every fifth draw after a burn-in of $\mathbf{5 0 , 0 0 0}$ iterations.

Variable Costs Models

\begin{tabular}{|c|c|c|c|c|c|c|c|c|}
\hline \multirow[b]{2}{*}{ Variable } & \multicolumn{4}{|c|}{ Model 4VC } & \multicolumn{4}{|c|}{ Model 5VC } \\
\hline & Mean & sd & $2.50 \%$ & $97.50 \%$ & Mean & sd & $2.50 \%$ & $97.50 \%$ \\
\hline Intercept & -1.225 & 0.127 & -1.501 & -0.999 & -1.144 & 0.091 & -1.334 & -0.975 \\
\hline W1 - ATCOs & 0.376 & 0.032 & 0.313 & 0.439 & 0.380 & 0.032 & 0.318 & 0.443 \\
\hline W2 - Non-ATCOs & 0.353 & 0.028 & 0.297 & 0.409 & 0.348 & 0.028 & 0.293 & 0.403 \\
\hline Y - Output & 0.246 & 0.066 & 0.120 & 0.370 & 0.256 & 0.059 & 0.142 & 0.370 \\
\hline K - Capital & 0.039 & 0.014 & 0.013 & 0.066 & 0.034 & 0.013 & 0.008 & 0.060 \\
\hline t - Time & 0.011 & 0.010 & -0.008 & 0.031 & 0.003 & 0.008 & -0.013 & 0.019 \\
\hline$t^{*} t$ & -0.001 & 0.001 & -0.003 & 0.000 & -0.001 & 0.001 & -0.003 & 0.000 \\
\hline Z1 - Area & 0.404 & 0.106 & 0.172 & 0.627 & 0.475 & 0.082 & 0.327 & 0.650 \\
\hline Z2 - Complexity & 0.003 & 0.026 & -0.049 & 0.054 & 0.001 & 0.026 & -0.050 & 0.053 \\
\hline Z3 - Variability & -0.088 & 0.202 & -0.481 & 0.314 & -0.168 & 0.197 & -0.556 & 0.215 \\
\hline D1 - Private & 0.283 & 0.359 & -0.602 & 0.764 & & & & \\
\hline D2 - Public & 0.270 & 0.180 & -0.173 & 0.561 & & & & \\
\hline Intercept & & & & & -0.160 & 0.195 & -0.555 & 0.209 \\
\hline D1 - Private & & & & & -0.228 & 0.657 & -1.675 & 0.896 \\
\hline D2 - Public & & & & & -0.172 & 0.569 & -1.397 & 0.841 \\
\hline Eta $(\eta)$ & -0.006 & 0.004 & -0.013 & 0.001 & & & & \\
\hline Sigma sq. u & 0.006 & 0.001 & 0.005 & 0.007 & 0.006 & 0.001 & 0.005 & 0.008 \\
\hline Lambda & 0.908 & 0.168 & 0.614 & 1.269 & 0.869 & 0.169 & 0.574 & 1.233 \\
\hline DIC & & & 764 & & & & 84 & \\
\hline
\end{tabular}

In Model 5VC, Lambda 2 and Lambda 3 (i.e. D1=1 and D2=1, respectively) are 0.814 and 0.823.

Total Costs Models

\begin{tabular}{|c|cccc|cccc|}
\cline { 2 - 9 } \multicolumn{1}{c|}{} & \multicolumn{4}{c|}{ Model 4TC } & \multicolumn{4}{c|}{ Model 5TC } \\
\hline Variable & Mean & sd & $\mathbf{2 . 5 0 \%}$ & $\mathbf{9 7 . 5 0 \%}$ & Mean & sd & $\mathbf{2 . 5 0 \%}$ & $\mathbf{9 7 . 5 0 \%}$ \\
Intercept & -1.324 & 0.114 & -1.558 & -1.116 & -1.276 & 0.103 & -1.487 & -1.092 \\
W1 - ATCOs & 0.351 & 0.032 & 0.287 & 0.414 & 0.352 & 0.031 & 0.290 & 0.414 \\
W2 - Non-ATCOs & 0.310 & 0.029 & 0.252 & 0.368 & 0.306 & 0.029 & 0.250 & 0.363 \\
W4 - Capital price & 0.007 & 0.015 & -0.022 & 0.036 & 0.012 & 0.014 & -0.015 & 0.040 \\
Y - Output & 0.200 & 0.068 & 0.071 & 0.330 & 0.209 & 0.062 & 0.083 & 0.325 \\
t - Time & -0.005 & 0.009 & -0.022 & 0.012 & -0.011 & 0.008 & -0.027 & 0.004 \\
t*t & 0.000 & 0.001 & -0.002 & 0.001 & 0.000 & 0.001 & -0.002 & 0.001 \\
Z1 - Area & 0.401 & 0.128 & 0.203 & 0.713 & 0.392 & 0.118 & 0.213 & 0.672 \\
Z2 - Complexity & 0.011 & 0.026 & -0.041 & 0.063 & 0.010 & 0.026 & -0.042 & 0.062 \\
Z3 - Variability & -0.165 & 0.198 & -0.554 & 0.221 & -0.182 & 0.197 & -0.560 & 0.210 \\
D1 - Private & 0.304 & 0.326 & -0.503 & 0.778 & & & & \\
D2 - Public & 0.241 & 0.274 & -0.509 & 0.611 & & & &
\end{tabular}




\begin{tabular}{|c|c|c|c|c|c|c|c|c|}
\hline Intercept & & & & & -0.275 & 0.197 & -0.674 & 0.096 \\
\hline D1 - Private & & & & & -0.308 & 0.659 & -1.747 & 0.823 \\
\hline D2 - Public & & & & & -0.284 & 0.574 & -1.519 & 0.738 \\
\hline Eta $(\eta)$ & -0.004 & 0.003 & -0.010 & 0.001 & & & & \\
\hline Sigma sq. u & 0.006 & 0.001 & 0.005 & 0.007 & 0.006 & 0.001 & 0.005 & 0.007 \\
\hline Lambda & 0.798 & 0.145 & 0.544 & 1.110 & 0.775 & 0.152 & 0.510 & 1.101 \\
\hline & \multicolumn{4}{|c|}{4774} & \multicolumn{4}{|c|}{4775} \\
\hline
\end{tabular}

In Model 5TC, Lambda 2 and Lambda 3 (i.e. D1=1 and D2=1, respectively) are 0.670 and 0.656.

Appendix C - Translog estimation results based on 150,000 draws with a thinning to every fifth draw after a burn in of 50,000 iterations.

Variable Costs Models

\begin{tabular}{|c|c|c|c|c|c|c|c|c|}
\hline \multirow[b]{2}{*}{ Variable } & \multicolumn{4}{|c|}{ Model 4VC } & \multicolumn{4}{|c|}{ Model 5VC } \\
\hline & Mean & sd & $2.50 \%$ & $97.50 \%$ & Mean & sd & $2.50 \%$ & $97.50 \%$ \\
\hline Intercept & -1.297 & 0.132 & -1.573 & -1.061 & -1.169 & 0.096 & -1.376 & -0.993 \\
\hline W1 - ATCOs & 0.364 & 0.033 & 0.299 & 0.430 & 0.372 & 0.033 & 0.307 & 0.438 \\
\hline W2 - Non-ATCOs & 0.420 & 0.032 & 0.359 & 0.482 & 0.411 & 0.032 & 0.349 & 0.473 \\
\hline Y - Output & 0.251 & 0.065 & 0.119 & 0.378 & 0.253 & 0.061 & 0.130 & 0.367 \\
\hline K - Capital & 0.046 & 0.017 & 0.013 & 0.078 & 0.036 & 0.016 & 0.004 & 0.068 \\
\hline $\mathbf{W} 1 * \mathbf{W} 1$ & 0.181 & 0.050 & 0.084 & 0.279 & 0.198 & 0.050 & 0.100 & 0.295 \\
\hline $\mathrm{W} 2 * \mathrm{~W} 2$ & 0.145 & 0.026 & 0.093 & 0.197 & 0.140 & 0.027 & 0.087 & 0.192 \\
\hline $\mathbf{Y} * \mathbf{Y}$ & 0.008 & 0.023 & -0.037 & 0.052 & -0.004 & 0.022 & -0.047 & 0.040 \\
\hline $\mathbf{K} * \mathbf{K}$ & -0.002 & 0.011 & -0.024 & 0.018 & -0.005 & 0.011 & -0.026 & 0.016 \\
\hline $\mathrm{W} 1 * \mathrm{~W} 2$ & -0.381 & 0.078 & -0.533 & -0.229 & -0.380 & 0.077 & -0.529 & -0.229 \\
\hline $\mathbf{W} 1 * \mathbf{Y}$ & 0.065 & 0.040 & -0.011 & 0.145 & 0.064 & 0.039 & -0.014 & 0.140 \\
\hline $\mathbf{W} 1 * K$ & 0.062 & 0.039 & -0.015 & 0.140 & 0.055 & 0.040 & -0.022 & 0.133 \\
\hline $\mathbf{W} 2 * \mathbf{Y}$ & -0.001 & 0.048 & -0.094 & 0.092 & -0.012 & 0.046 & -0.101 & 0.078 \\
\hline $\mathrm{W} 2 * \mathrm{~K}$ & -0.049 & 0.040 & -0.128 & 0.029 & -0.032 & 0.039 & -0.109 & 0.044 \\
\hline $\mathbf{Y} * \mathbf{K}$ & -0.002 & 0.019 & -0.037 & 0.035 & -0.006 & 0.018 & -0.041 & 0.029 \\
\hline t - Time & 0.022 & 0.009 & 0.005 & 0.039 & 0.008 & 0.007 & -0.006 & 0.023 \\
\hline$t^{*} t$ & -0.002 & 0.001 & -0.003 & -0.001 & -0.002 & 0.001 & -0.003 & 0.000 \\
\hline Z1 - Area & 0.276 & 0.109 & -0.009 & 0.459 & 0.350 & 0.093 & 0.160 & 0.545 \\
\hline Z2 - Complexity & 0.011 & 0.024 & -0.036 & 0.058 & 0.008 & 0.025 & -0.041 & 0.057 \\
\hline Z3 - Variability & 0.220 & 0.193 & -0.159 & 0.602 & 0.142 & 0.196 & -0.245 & 0.531 \\
\hline D1 - Private & 0.362 & 0.260 & -0.230 & 0.822 & & & & \\
\hline D2 - Public & 0.315 & 0.174 & -0.077 & 0.617 & & & & \\
\hline Intercept & & & & & -0.135 & 0.197 & -0.535 & 0.237 \\
\hline D1 - Private & & & & & -0.309 & 0.656 & -1.749 & 0.821 \\
\hline D2 - Public & & & & & -0.327 & 0.572 & -1.557 & 0.688 \\
\hline
\end{tabular}




\begin{tabular}{|c|cccc|cccc|} 
Eta $(\boldsymbol{\eta})$ & -0.009 & 0.003 & -0.016 & -0.003 & & & & \\
& & & & & & & & \\
Sigma sq. u & 0.005 & 0.000 & 0.004 & 0.006 & 0.005 & 0.000 & 0.004 & 0.006 \\
Lambda & 0.930 & 0.177 & 0.624 & 1.314 & 0.891 & 0.175 & 0.586 & 0.878 \\
\hline
\end{tabular}

In Model 5VC, Lambda 2 and Lambda 3 (i.e. D1=1 and D2=1, respectively) are 0.770 and 0.724.

Total Costs Models

\begin{tabular}{|c|c|c|c|c|c|c|c|c|}
\hline \multirow[b]{2}{*}{ Variable } & \multicolumn{4}{|c|}{ Model 4TC } & \multicolumn{4}{|c|}{ Model 5TC } \\
\hline & Mean & sd & $2.50 \%$ & $\mathbf{9 7 . 5 0 \%}$ & Mean & sd & $2.50 \%$ & $97.50 \%$ \\
\hline Intercept & -1.345 & 0.110 & -1.564 & -1.131 & -1.281 & 0.099 & -1.477 & -1.091 \\
\hline W1 - ATCOs & 0.384 & 0.033 & 0.319 & 0.449 & 0.388 & 0.034 & 0.322 & 0.456 \\
\hline W2 - Non-ATCOs & 0.361 & 0.032 & 0.298 & 0.424 & 0.358 & 0.032 & 0.294 & 0.421 \\
\hline W4 - Capital price & 0.044 & 0.018 & 0.010 & 0.079 & 0.046 & 0.017 & 0.012 & 0.080 \\
\hline Y - Output & 0.184 & 0.063 & 0.063 & 0.307 & 0.199 & 0.062 & 0.077 & 0.318 \\
\hline $\mathrm{W} 1 * \mathrm{~W} 1$ & 0.064 & 0.049 & -0.032 & 0.161 & 0.067 & 0.050 & -0.030 & 0.166 \\
\hline $\mathrm{W}_{2} * \mathrm{~W} 2$ & 0.124 & 0.030 & 0.066 & 0.185 & 0.123 & 0.030 & 0.063 & 0.183 \\
\hline $\mathrm{W} 4 * \mathrm{~W} 4$ & 0.027 & 0.007 & 0.014 & 0.040 & 0.027 & 0.007 & 0.014 & 0.040 \\
\hline $\mathbf{Y} * \mathbf{Y}$ & -0.011 & 0.019 & -0.047 & 0.026 & -0.018 & 0.018 & -0.053 & 0.016 \\
\hline $\mathrm{W} 1 * \mathrm{~W} 2$ & -0.243 & 0.077 & -0.394 & -0.092 & -0.248 & 0.079 & -0.400 & -0.095 \\
\hline $\mathrm{W} 1 * \mathrm{~W} 4$ & -0.057 & 0.042 & -0.139 & 0.025 & -0.066 & 0.042 & -0.148 & 0.016 \\
\hline $\mathbf{W} 1 * \mathbf{Y}$ & 0.134 & 0.034 & 0.067 & 0.199 & 0.136 & 0.034 & 0.071 & 0.203 \\
\hline $\mathrm{W} 2 * \mathrm{~W} 4$ & -0.005 & 0.030 & -0.064 & 0.053 & -0.005 & 0.030 & -0.064 & 0.054 \\
\hline $\mathrm{W} 2 * \mathrm{Y}$ & -0.064 & 0.034 & -0.130 & 0.002 & -0.062 & 0.033 & -0.128 & 0.004 \\
\hline $\mathrm{W} 4 * \mathbf{Y}$ & 0.041 & 0.015 & 0.011 & 0.070 & 0.041 & 0.015 & 0.011 & 0.071 \\
\hline t - Time & -0.001 & 0.009 & -0.018 & 0.017 & -0.006 & 0.007 & -0.021 & 0.009 \\
\hline$t * t$ & -0.001 & 0.001 & -0.002 & 0.001 & -0.001 & 0.001 & -0.002 & 0.001 \\
\hline Z1 - Area & 0.308 & 0.101 & 0.137 & 0.530 & 0.279 & 0.096 & 0.095 & 0.478 \\
\hline Z2 - Complexity & 0.027 & 0.024 & -0.019 & 0.074 & 0.026 & 0.024 & -0.020 & 0.073 \\
\hline Z3 - Variability & 0.110 & 0.189 & -0.258 & 0.482 & 0.113 & 0.189 & -0.260 & 0.482 \\
\hline D1 - Private & 0.254 & 0.461 & -1.090 & 0.819 & & & & \\
\hline D2 - Public & 0.175 & 0.439 & -1.282 & 0.595 & & & & \\
\hline Intercept & & & & & -0.246 & 0.195 & -0.642 & 0.123 \\
\hline D1 - Private & & & & & -0.378 & 0.659 & -1.827 & 0.757 \\
\hline D2 - Public & & & & & -0.419 & 0.571 & -1.646 & 0.595 \\
\hline Eta $(\eta)$ & -0.003 & 0.003 & -0.008 & 0.002 & & & & \\
\hline Sigma sq. u & 0.005 & 0.000 & 0.004 & 0.006 & 0.005 & 0.000 & 0.004 & 0.006 \\
\hline Lambda & 0.783 & 0.142 & 0.534 & 1.087 & 0.797 & 0.155 & 0.526 & 1.131 \\
\hline
\end{tabular}

In Model 5TC, Lambda 2 and Lambda 3 (i.e. D1=1 and D2=1, respectively) are 0.643and 0.589. 

2018-03-11

\section{A cost-efficiency analysis of European air navigation service providers}

Dempsey-Brench, Zara

Elsevier

Dempsey-Brench Z, Volta N. (2018) A cost-efficiency analysis of European air navigation service providers, Transportation Research Part A: Policy and Practice, Vol. 111, May 2018, pp. 11-23 http://dx.doi.org/10.1016/j.tra.2018.02.019

Downloaded from Cranfield Library Services E-Repository 